$\mathbb{T}$ periodica polytechnica

\author{
Social and Management Sciences \\ $15 / 1(2007) 31,42$ \\ doi: 10.3311/pp.so.2007-1.04 \\ web: http://www.pp.bme.hu/so \\ (c) Periodica Polytechnica 2007
}

RESEARCH ARTICLE

\section{Kuhn's Darwinism - from a darwinian point of view}

\author{
Dániel Paksi
}

Received 2008-09-14

\begin{abstract}
The purpose of Kuhn in The Structure of Scientific Revolutions (SSR) is twofold. On the one hand, he aims to displace the goal-directed science-development model of the neopositivists, and on the other, he wants to retain the idea of progress in science. He states that the latter is analogous to that of Darwinian evolution. Here I will claim that Kuhn thinks about the issue of evolution in a neopositivistic/Neo-Darwinian way and thus interprets the phenomenon of change in science as a (nondevelopmental, non-goal-directed) temporal process. Nevertheless, trying to support Kuhn's own science-development model with a genuinely Darwinian theory (as I am putting forward here) might be a fruitful and coherent project. In order to do so, one has to interpret the theory of evolution in a nonneopositivistic/non-Neo-Darwinian, indeed 'Kuhnian' way, as it is done in cybernetic and system-theoretical approaches which displaced the neopositivistic/Neo-Darwinian interpretation of evolutionary theory at about the same time when Kuhn and others displaced neopositivism in the philosophy of science. But, since Kuhn is committed to the neopositivistic/Neo-Darwinian interpretation of the theory of evolution, we cannot regard his work as a proper "evolutionary view of science".
\end{abstract}

\section{Keywords}

cybernetics $\cdot$ Darwinian evolution $\cdot$ goal-directed $\cdot$ sciencedevelopment $\cdot$ system theories

\section{Acknowledgement}

I am grateful to Márta Fehér, Vera Békés, Benedek Láng, Viktor Binzberger, Péter Fazekas, János Laki, Gábor Zemplén, Viktor Bodnár and especially George Kampis for useful comments and suggestions on earlier drafts of this paper.

\section{Dániel Paksi}

Department for the History and Philosophy of Science, BME, Budapest, 1111, Stoczek József utca 2-4, Hungary

e-mail: daniel.paksi@filozofia.bme.hu

\section{Kuhn and Darwinism}

\subsection{A question arises}

In The Structure of Scientific Revolutions (SSR) Kuhn argued for the displacement of the goal-directed, teleological sciencedevelopment model of the neopositivists. In his "evolutionary view of science" the "evolution of the scientific ideas" is called analogous to Darwinian evolution (SSR: 171-173). At the same time, Kuhn states that the result of scientific evolution is a non-cumulative, non-goal-directed, incommensurabilistic science. But this result is in conflict with the Darwinian view of science and culture. What is the source of the contradiction?

Before going into the details, let us take a closer look at Kuhn's Darwinian analogies. In the quotation below, we can find both the developmental and the evolutionary tree analogies.

"The process described in Section XII as the resolution of revolutions is the selection by conflict within the scientific community of the fittest way to practice future science. The net result of a sequence of such revolutionary selections, separated by periods of normal research, is the wonderfully adapted set of instruments we call modern scientific knowledge. Successive stages in that developmental process are marked by an increase in articulation and specialization. And the entire process may have occurred, as we now suppose biological evolution did, without benefit of set goal, a permanent fixed scientific truth, of which each stage in the development of scientific knowledge is a better exemplar." (SSR: 172-173.)

Kuhn states that the selection of scientific theories by scientific revolutions leads to an evolutionary tree structure of science and that the development of science is a non-goal-directed process of change toward no goal which, in a paradoxical way, still implies for him that scientific progress exists. In Kuhn's surprising words: "That is not a relativist's position, and it displays the sense in which I am a convinced believer in scientific progress." (SSR: 206.)

\subsection{What evolution and Darwinism are?}

In the $19^{\text {th }}$ century, evolutionary theories, as well as other contemporary theories of nature, culture and science, were influenced by the notion of progress (e.g. Hegel, A. Comte, 
H. Spencer). Thus evolution meant a teleological process of progress during which the highest evolved man necessarily developed from the primitive germ plasm of the beginnings. This picture was significantly influenced by the phenomenon of ontogeny where if the necessary conditions are given then an adult human necessarily develops from the initial zygote because of her DNA in which such general regularities work which unambiguously control and determine the stages, the process, and the end of development.

The fundamental and important difference between these two ways of development is that in the case of the theories of progress, the development is determined by an absolute, external principle - set by God, Nature, rationality or something else - while in the case of ontogeny by a non-absolute, internal one - set by evolution. Thus the earlier in contrast to the latter goes towards an - absolute and external - goal, however, as we see it in the case of the latter, there is no need of such goal to a necessary, goal-directed development.

In contrast to the early evolutionists Darwin himself pursued research only on those material mechanisms by which he could explain the appearance of new species 1 existence of which at least one of them - he originally supposed ${ }^{2}$ In his work in accordance with the contemporary Newtonian paradigm - and in contrast with the theories of progress - he did not presume any teleological principle in evolution as the early evolutionists did. And because of this he avoided the use of the contemporary concept of evolution - and substantiated a new one.

Darwin based his mechanism of natural selection on the Malthusian demographical mathematical model where the reproduction follows a geometrical series while the development of means of production is just linear thus the latter process restricts the population-growth. In connection with the descent of species it means that the environmental resources restrict the increase of species - several newborn individuals will die well before their maturity - thereby if there is difference between the individuals, so there is variability, and if there is no sufficient environmental resources, so there is a restricting factor then the mechanism of natural selection begins to work and with the extinction of individuals who are different in contrast to the survivors the given species begin to change. This is the logical structure of natural selection from which two things follows. First, the process of replication is not a precondition for natural selection only for the descent of species - reproduction is the natural process of increasing - , and it works inside of one generation if its preconditions - variability, restricting factor -

\footnotetext{
${ }^{1}$ see The Origin of Species by Means of Natural Selection, or the Preservation of Favoured Races in the Struggle for Life (Darwin, 1872)

2 "There is grandeur in this view of life, with its several powers, having been originally breathed by the Creator into a few forms or into one; and that, whilst this planet has gone cycling on according to the fixed law of gravity, from so simple a beginning endless forms most beautiful and most wonderful have been, and are being, evolved." (Darwin, 1872: 429)
}

are given 3 Second, since both of the preconditions of the process are contingent, - the different features of individuals are the consequence of a random process and the conditions of environment and its changing are occasional - in the long run, the natural selection itself will also be a contingent, changing process from which no development follows. [7]

Then the followers of the Neo-Darwinian theory (e.g. T. Dobzhanshy, J. Huxley, E. Mayr, etc.) which became the ruling evolutionary theory of the 20th century took over both the mechanism of natural selection and the concept of evolution. In this theory of evolution the mechanism of natural selection is combined with the theory of genetics. This means, on the one hand, that they connected the formation of different individuals with the process of replication thereby they explained the occurrence of variability 4 , and, on the other one, that they reduced the subject of evolutionary process to the genome 5 [13, 19, 28]. However, the logical structure of the process has remained the same ${ }^{6}$ the mechanism of natural selection is determined by the two contingent factors of variability and of restricting insufficiency, thus, the Neo-Darwinian evolutionary theory has remained also a contingent changing process from which naturally no development follows. [10,29, 30

However, some critics of this view do not accept that the mechanism of natural selection, a contingent, changing process can explain any development in evolution, for example, Michael Polányi, before SSR, states that Darwin did not only displace an old, out-of-date teleological - absolute and external - principle in the explanation of evolution but unfortunately he threw any kind of necessary principle away. "Darwinism has diverted attention for a century from the descent of man by investigating the conditions of evolution and overlooking its action. Evolution can be understood only as a feat of emergence." (Polányi, 1962: 390) [32]

At the same time, the Neo-Darwinians, of course, think that they explained the development in evolution. Moreover, they interpret it many times as a progress towards no goal - in contrast to the teleological progress of the early evolutionists. See, for example, Mayr's Evolutionary Progress without Final Causes subsection (Mayr, 1991: 62-65) [28], or in Francisco Ayala's words the natural selection is necessarily teleological in itself (Ayala, 1998: 32-43) [2] only "the over-all process of evolution cannot be said to be teleological in the sense of proceeding towards certain specified goals..." (Ayala, 1998: 42) [2].

So, "a good evolutionary theory is antidevelopmentalist and antiteleological..." [38]. However, on the other hand, the no-

\footnotetext{
3 As a matter of fact that in the case of many offspring the competitor is not an individual from another species or an older one but another one from the same generation or as well its littermate.

${ }^{4} \mathrm{So}$, the source of that became a lower level random physical chemical process called mutation.

5 Or to the genes, as Dawkins, for example. 5

6 Apart from that the formation of difference is now exclusively attached to the birth of new generation.
} 
tion of progress and the teleological approach can be separated from the idea of a cumulative, purely developmental and goaldirected evolutionary process 7 , as this was shown by the cybernetics and system theories (e.g. Bertalanffy, Wiener, Ashby) influence of which gradually displaced the neopositivistic/NeoDarwinian interpretation in evolutionary theories during the $60 \mathrm{~s}$ and 70s (see e.g. [1, 3, 4, 46] ). Nowadays, we can find the influence of this novel interpretation of evolutionary theories - for example - in the works of Michael Tomasello (1999; 2005), [42, 43] Merlin Donald (1991) [14], Jared Diamond (1993; 1998)[11, 12] or Vilmos Csányi (1982) [6] [8 But, of course, the Neo-Darwinian interpretation of evolutionary theories is still alive and dominant and we can find it in the works of such great authors as George C. Williams $(1966,1992)$ [47], Richard Dawkins (1976) [8], John Maynard Smith (1997) [27], Daniel C. Dennett (1995) [9] or, naturally, Ernst Mayr (1991, 2001) [29, 30].

\subsection{The appearance of Kuhn in the field of the philosophy of science}

After the turn of the century and the First World War, the notion of progress was pushed into the background and a sharp demarcation criterion was suggested by the neopositivists, separating science from the rest of culture and nature. Within the well-defined territory of science, neopositivists tried to save the notion of progress and the possibility of an incessantly developing, cumulative and teleological science (e.g. R. Carnap, K. Popper, etc.). Thus the evolutionary process - outside of the range of the demarcation criterion - became a matter of simple temporal change (see e.g. [34-36] ).

Then, in the 60s, Kuhn, who was a physicist and was inspired by his research on the history of natural science, displaced the notion of goal-directed, continuous science-development as proposed by the neopositivists 9 His work, however, remained largely in the field of natural science ${ }^{10}$ In the SSR, except for a few examples mostly from chemistry, all his examples were taken from physics. There is no sign that he was taking the new interpretation of the theories of evolution - influenced by cybernetics and system theories - into consideration. When he refers to Darwin and the theories of evolution, Kuhn thinks about them

\footnotetext{
${ }^{7}$ I think, in a sense, Kuhn has the same purpose when he states that the development of science - with his paradoxical words: 'the progress of science' - is analogous to the non-teleological and non-progress interpretation of evolution. However, he draws a parallel between a process of development and a process of change - according to the neopositivistic/Neo-Darwinian interpretation of evolution - that necessarily leads to contradiction.

${ }^{8}$ In the third section I will put a more detailed picture of this interpretation in connection with Kuhn's developmental analogy.

9 Along with others, of course, e.g. Stephen Toulmin (1961) 44], Norwood Russell Hanson (1961) [17] or later Paul Feyerabend (1997) [15].

${ }^{10}$ In the field of social science, the influence of the neopositivists was weaker, thus, in accordance with that, there was little place for a critic against them. In this field, the notion of progress remained a determinant one until the $60 \mathrm{~s}$ and 70 s, when the influence of the new interpretation of evolutionary theories displaced it.
}

in an old-fashioned neopositivistic/Neo-Darwinian 11 way and interprets the evolution as a non-developing, non-goal-directed, process of change towards no goal and contrasts it only with the notion of progress (e.g. SSR: 171-173).

Naturally, the fact, that these two simultaneous events Kuhn's appearance in philosophy and history of science and the influence of Norbert Wiener and the cybernetics in evolutionary theories and e.g. in cognitive psychology - were not accidental, but the consequence of the scientific, social and political changes of the 40s, 50s and 60s after the shocking Second Word War. In this sense, we can say that there was a 'Kuhnian revolution' in evolutionary theories during the 60s and 70s, despite the fact that Kuhn himself presumably did not recognize that. And this latter is, I believe, the source of the contradictions and confusions emerging in connection with the Darwinian interpretations and analogies of SSR, since Kuhn himself, in contrast to his physics and philosophy of science, in the case of the theory of evolution, did not revise the prevailing neopositivistic/NeoDarwinian interpretation. This will be clear for us, for example, in connection with the crucial concept of progress. Ernst Mayr, the famous Neo-Darwinian, "Darwin of the $20^{\text {th }}$ century", interprets the Neo-Darwinian evolutionary changing process as a progress towards no goal exactly in the same way as Kuhn himself does.

\subsection{Change or progress?}

So, in SSR Kuhn argues with the neopositivists that there are no universal, necessary standards in science which determine its goal and progress, only different, incommensurabilistic paradigms - from which no goal and progress follow. However, he does not want to be a relativist, and, in a radically new sense, tries to retain the idea of progress - as it appears in Darwinian evolution (developmental analogy). But he thinks about the issue of evolution in such a way that it means just a "blind", temporal process of change - a contingent mechanism - and does not imply any determinable progress or development ${ }^{12}$ The instrumental character of this view is the reason why the neopositivists - mainly Popper - think about this interpretation affectively ${ }^{13}$, because they assert that there are universal, necessary standards in science which determine its goal and progress and Darwinian or Neo-Darwinian natural selection is simply the main, "blind" mechanism of this progress - selection goes by universal standards (see e.g. the section III of Popper's The Rationality of Scientific Revolutions (1981: 84-87 [35] ${ }^{14}$.

\footnotetext{
${ }^{11}$ There is an interesting and important question why the neopositivistic and Neo-Darwinian, and, of course, Kuhnian, interpretations of evolutionary theories are parallels, at least from our aspects, but in this paper we have no possibility to investigate it in detail and it has not an effect on my main argumentation that Kuhn uses an inadequate evolutionary theory for his purpose.

${ }^{12} \mathrm{As}$ we have seen it in the 1.2 subsection, natural selection is directed by two random factors (conditions): mutations and the contingent environment. There is no other fundamental principle in action in this interpretation of evolution.

13 Although this already follows from their demarcation criterion.

14 ,Lowering the degree of 'blindness'."
} 
However, and this is important, in Kuhn's science-development model there are no such universal and necessary standards but entirely different, incommensurabilistic paradigms, thus, in this case natural selection itself remains a goal-less instrument - selection goes by the standardless scientific revolutions (e.g. see the citation in the 1.1 subsection).

All these are clearly discernible from Carnap's brief letter written to Kuhn in 1962 after reading the completed manuscript of SSR 15

„I found very illuminating the parallel you draw with Darwinian evolution: just as Darwin gave up the earlier idea that the evolution was directed towards a predetermined goal, men as the perfect organism, and saw it as a process of improvement by natural selection, you emphasize that the development of theories is not directed toward the perfect true theory, but is a process of improvement of an instrument. In my own work on inductive logic in recent years I have come to a similar idea: that my work and that of a few friends in the step for step solution of problems should not be regarded as leading to "the ideal system", but rather as a step for step improvement of an instrument. Before I read your manuscript I would not have put it in just those words. But your formulations and clarifications by examples and also your analogy with Darwin's theory helped me to see clearer what I had in mind." (Reisch, 1991: 267 [37]).

Carnap, who never dealt specifically with the idea of Darwinian evolution but interprets it as a process of change as does Kuhn, at once recognizes the opportunity in Kuhn's developmental analogy for himself and for the neopositivists to explain the mechanism of scientific progress. In this interpretation evolution is going toward no (independent, external and absolute) goal and thus it can be directed by internal, universal and necessary standards and can be the main mechanism of science. Kuhn interprets correctly that from the external, absolute principles of the theories of progress and the internal, universal standards of the neopositivists the same teleological, thus goal-directed, progress follows - towards an absolute, external goal ("the ideal system") and directed by an internal, universal goa ${ }^{16}-$, however, as I will put forward in this paper, he does not recognize that goal-directedness is not the fundamental problem for him but the external-absolute or internal-universal standards behind it. He does not recognize it, because he interprets correctly that from these two different principles the same teleological progress follows only because, as a matter of fact, he understands both of them as a teleological progress towards an absolute, external goal. For him like for the Neo-Darwinians only this contrasting is important.

So, non-teleological "scientific development is like Darwinian evolution, a process driven from behind rather than pulled towards some fixed goal to which it goes ever close." (Kuhn, 2002: 115 [23]) But, as we see it, a "process driven

\footnotetext{
15 Which was interpreted by Kuhn as a "mere politeness" (Kuhn, 1993: 313) 21]

The latter is parallel to the ontogeny! See it in the 1.2 subsection.
}

from behind" can be teleological, if there are independent, universal, necessary standards behind it and does not go towards any "fixed goal" or truth. And, what is more, supposedly this is why he does not recognize that for a non-relativistic, welldetermined notion of development - indeed, progress in a radically new sense - he has to define his own fundamental - but not absolute and universal - principle which directs the progress or development - or otherwise it remains a simple, temporal process of change 17

\subsection{After SSR}

After SSR Kuhn's point of view was significantly changed in several aspects. For example, he stated that his "repeated talk of gestalt switches" in SSR was a "mistake" (Kuhn, 1993: 328 [21]), so, the main importance of paradigm shifts would be seen to be in the generation of new sciences, rather than in the replacement of paradigms within the same speciality, and, the concept of lexicon was introduced, thus, incommensurability became "a growing conceptual disparity between the tools deployed in the two specialities" (Kuhn, 2002: 120 [23]). These mean in connection with our question that the parallel with Darwinian evolution needs to be made much stronger, the new scientific specialities evolve as new species - thus, the evolutionary tree analogy becomes more important in contrast to SSR. This choice is entirely comprehensible and necessary because as we will see (in the second section) the evolutionary tree analogy is fruitful to clarify some problems and contradictions in contrast to the developmental analogy (third section), however, it can not explain the development in science (see 2.6 subsection) which was Kuhn's first intention when he turned to a Darwinian analogy in SSR (171-173).

Kuhn already wished before the 2nd edition of SSR that "people took the \{Darwinian\} metaphor more seriously" (Kuhn, 1977: 508 [20]) but in his last interview he had to state that "no one took it seriously" (Kuhn, 2002: 307 [24]). The secondary literature does not understand Kuhn's work from a Darwinian point of view based on his evolutionary analogy (see e.g. Fuller, 2000; Hoyningen-Huene, 1993; Bird, 2000 [5, 16, 18]) or if they try - at least in part - they do not find it appropriate, for example, Wes Sharrock and Rupert Read find it "entirely unpersuasive, and unnecessary" (Sharrock, 2002: 193)[40]. Elevating exception is the work of Hungarian author János Laki, at the same time, he also uses the Darwinian mechanism of natural selection only to describe the micro processes of scientific change in the scientific community [26] and not to define the macro development of science in accordance with Kuhn's first intention.

However, I believe that the idea of supporting Kuhn's sciencedevelopment model with a Darwinian theory - and with not only a simple analogy - might be a fruitful and consistent one, but in order to do so, one has to interpret the theory of evolution in a non-neopositivistic/Non-Neo-Darwinian, indeed 'Kuhnian'

\footnotetext{
17 As it is argued, for example, by Polányi (1962) 32. Natural selection is in itself just a "condition" of evolution and not its principle ("action").
} 
way, as it is done by the cybernetic and system-theoretical approaches, and, of course, an evolutionary theory of this kind has to define the principle of progress or development for the Kuhnian science-development model 18

So, in the second section, I will examine Kuhn's evolutionary tree analogy which can be useful to clarify some problems and contradictions in SSR but which can not be sufficient in itself to explain the development in science. Then, in the third section, the developmental analogy and the problem of goal-directedness will be investigated which in turn will help us to understand Kuhn's interpretation of Darwinian evolutionary theory. In order to achieve this, for the problem of goal-directedness we will draw an analogy between the Kuhnian criticism of the traditional, neopositivistic interpretation of the Newtonian paradigm and our Darwinian criticism of the neopositivistic/Neo-Darwinian interpretation of the Darwinian evolutionary theory, used by Kuhn without proper care and because of that he could not reach his goal to successfully explain the development in science.

\section{The evolutionary tree analogy}

\subsection{The problem of general values and persistent} paradigms

Kuhn asserts two different statements about paradigms. On the one hand - and this is the more eye-catching - he attaches the components of the disciplinary matrix to the different scientific paradigms which are held incommensurable without unambiguous 'passages' amongst them. But on the other hand, Kuhn states clearly that within the different paradigms there also exist general scientific values - "... they do much to provide a sense of community to natural scientists as a whole (SSR: 184)" - e.g.:

"...theories: they must, first and foremost, permit puzzleformulation and solution; where possible they should be simple, self-consistent, and plausible, compatible, that is, with current theories deployed. (...) ...predictions: they should be accurate; quantitative predictions are preferable to qualitative ones; whatever the margin of permissible error, it should be consistently satisfied in a given field; and so on." (SSR: 185.)

How is it possible that the paradigms are incommensurable and the general scientific values are not?

Analogously to this, the question arises, how we can speak about the transition to a new paradigm - e.g. in the case of Priestley and Lavoisier - when Kuhn clearly asserts that, at the same time, the Newtonian paradigm, of universal validity, remains unchanged until the end of the transition?

We may find answers to these contradictions from Kuhn's own evolutionary tree analogy if we take a closer look.

\footnotetext{
18 As it was required by Polányi who stated that the ordering principle of evolution was the "potentiality of stable open system" (Polányi, 1962: 384 32]). Thus in his philosophy the idea of evolution is not only an analogy but a fundamental base.
}

\subsection{The tree of science}

We have seen that Kuhn states that there exist general scientific values which "provide a sense of community to natural scientists as a whole". This could mean that there are two levels of paradigms. First, the higher level of the general paradigm of science, determined by the general scientific values and second, the lower level of particular scientific paradigms, which are equal and incommensurable. But, since the different paradigms branch out from each other as the branches of an evolutionary tree (SSR: 205), the picture is much more complicated than that.

Kuhn identifies the different specialities, scientific communities and paradigms as follows (SSR: 176-177).

"A paradigm is what the members of a scientific community share, and, conversely, a scientific community consists of men who share a paradigm. (...) Scientific communities can and should be isolated without prior recourse to paradigms; the latter can then be discovered by scrutinizing the behaviour of a given community's members. (...) Most practicing scientists respond at once to questions about their community affiliations, taking for granted that responsibility for the various current specialities is distributed among groups of at least roughly determinate membership. (...) A scientific community consists, on this view, of the practitioners of a scientific speciality. 19 (SSR: 176-177)

And, "... communities in this sense exist, of course, at numerous levels. The most global is the community of all natural scientists...", which is the trunk of the evolutionary tree and which is held together by the general scientific values. "At only a slightly lower level the main scientific professional groups are communities: physicists, chemists, astronomers, zoologists, and the like." Which are the main branches of the evolutionary tree and which are separated by the main specialities of current science. Then, at even a more lower level, there are the more important subgroups, e.g. "organic chemists, and perhaps protein chemists among them, solid-state and high-energy physicists, radio astronomers and so on." (SSR: 177.)

There is no need to continue this, to recall more details of Kuhn's evolutionary tree analogy, or to examine whether he describes scientific specialities rightly. The point of interest for us is that it is clear from these quotations that the different paradigms derive from each other, according to their importance and validity, by the selection mechanism of scientific revolutions.

We can also find the same picture of the structure of science to be present in the case of the exemplars, when Kuhn says that:

"All physicists, for example, begin by learning the same exemplars... As their training develops, however, the symbolic generalizations they share are increasingly illustrated by different exemplars. Though both solid-state and field-theoretic physicists share the Schrödinger equation, only its more elemen-

\footnotetext{
${ }^{19}$ In the same place, this classification is called by Kuhn: „the intuitive notion of community."
} 
tary applications are common to both groups.” (SSR: 187.)

He also claims that "more than other sorts of components of the disciplinary matrix, differences between sets of exemplars provide the community fine-structure of science.'20 (SSR: 187.)

\subsection{The new sense of paradigm}

This may be true in the case of applying the notion to shared scientific theories - we have seen this above. However, the different scientific specialities have not just shared but also unshared scientific theories, by which one can traditionally differentiate them from each other. Of course, this is not too amazing since without such unshared scientific theories there wouldn't exist different scientific specialities at all. Kuhn himself, however, is interested in the new sense of paradigm and not in the well-known distinctive role of scientific theories.

The old sense of paradigm, which is later called 'disciplinary matrix' in the postscript of the second edition of SSR, also includes the scientific theories, but the new sense of paradigm, which is much more important for Kuhn, is only the fourth sort of element of the disciplinary matrix, namely, the 'exemplars' (SSR: 186-187). (The first three are the 'symbolic generalizations', 'metaphysical paradigms' and 'values' (SSR: 182-184).)

So Kuhn is interested in neither the scientific theories nor the disciplinary matrix - paradigms in the old sense - but in the exemplars - paradigms in the new sense - and their importance and distinctive role in the life of scientific communities. In other words, he is not interested in the distinctive role, evolutionary tree structure and descent of scientific theories but instead of the conceptual roles and application methods of the mechanism of science which are determined by the exemplars 21

Consequently, in the case which we have seen above, Kuhn also concentrates only on the distinctive role of the exemplars, whereas the tree structure of science is of no significance for him. And it follows from this point that it is not here that the evolutionary analogy and the tree structure of science appear in Kuhn's thinking. These two analogies are instead just ingredients of an intuitive answer to the above-mentioned questions. And they are not elaborated and are not contemplated because of Kuhn's essentially different interest ${ }^{22}$

\subsection{General paradigmatic values}

Before drawing our conclusion, it is worth stopping here. Although the general scientific values are given a prominent place

\footnotetext{
20 May be it is worth noticing that in contrast to the previous quotation which is 10 pages earlier in the SSR - here the scientific community is formed by all the physicists.

21 This interest remains also the same after SSR when he describes the evolving of new specialities as a narrowing process of the lexical structure.

22 The evolutionary analogies are also problematic because of their biological nature, since the development of science is, of course, not a biological but a cultural process with a very different heredity mechanism. The source of the accidental successfulness of the biological analogies is that in the case of natural science - to which the SSR only refers - the final subjects are not cultural as in the case of biological evolution.
}

in the structure of science by Kuhn, they are also not elaborated because of his different interest.

We have already seen Kuhn's examples at the beginning of the second section. However, in a sense, the first sort of element of the disciplinary matrix ('symbolic generalizations') belongs to these general values, because every paradigm of natural science uses symbolic generalizations when formalizing scientific theories. And what may be more important is mathematizing them. In Kuhn's view, in the Antiquity, paradigms have emerged in those branches of science where the application of mathematics - of course, not in a modern sense - was already at an advanced level, e.g.: astronomy, ancient statics, dynamics and geometrical optics (SSR: 15-16.).

Margaret Morrison states that the applications of mathematics and mathematical formalism have key importance in unifying different scientific theories (Morrison, 2000: 193.)[31] Kuhn's excellent example for this is Newton's unifying the celestial and the terrestrial mechanics 23

Beyond mathematics, the general scientific values of interest include logic whose fundamental theorems are explicitly or implicitly used by all the natural sciences.

\subsection{Conclusion of the evolutionary tree analogy}

So there are two possibilities for a new branch of science to evolve:

1 The specialization of a given higher level branch of science 'main paradigm' - into a lower level branch of science (e.g. SSR: 172.).

2 The linking of some lower level branches of science into a higher level branch of science. (This does not mean the end for the lower level branches of science, just the development of a main overall paradigm, e.g. SSR: 15,95 .).

Thus, for example, the influence of Newton's Principia on chemistry and the corpuscular standards at the end of the 18th century is in accordance with the first possibility, while its decisive role in physics the end of the 17th and the first half of the 18 th centuries is in accordance with the second possibility.

So, the evolutionary tree structure of paradigms allows a comparison of the different paradigms with each other via the general scientific values. However, this does not mean that the paradigms at the same level would be commensurable (consider e.g. Lavoisier's and Priestley's theories) or that any values or general values exist outside any sorts of paradigm. There are no

\footnotetext{
23 Though Morrison's example is not the Principia but The Origin of Species in which this key role is performed by the Malthusian demographical mathematical model. (The reproduction, as we have seen in the 1.2 subsection, follows a geometrical series while the development of means of production is just linear and the natural selection put an end to this difference - forming a given species, ecological system or population by the process.) The application of the Malthusian model made it possible for the Darwinian evolutionary theory to unify several disciplines and their consequences: geology, palaeontology, geography, morphology, embryology, etc. (Morrison, 2000: 192-209]31])
} 
universal, necessary standards or values - as in the theories of the neopositivists - ; a value within a paradigm can function as a general value just because it has general validity over the lower level, derived paradigms and although we can find it within every lower level, derived paradigms it still are determined by the higher level paradigm 24

The evolutionary tree analogy can also explain how a paradigm can remain unchanged while, at the same time, there is a transition to a new paradigm. The unchanged and the changing paradigms are not at the same level - as we have seen this possibility in the case of Lavoisier, whose work on chemistry induced a change of paradigm while the main Newtonian paradigm remained unchanged.

Consequently, the evolutionary tree analogy is fruitful in the case of explanation of a few Kuhnian problems and contradictions; however, Kuhn is not interested in the old sense of paradigm and the tree structure of scientific theories but in the distinctive role of the exemplars, mostly in the case of the same-level-paradigms, which, in accordance with their meaning, follow each other by the process of scientific revolutions. It is important to make it clear that the evolutionary tree analogy is not the revolutionary point of the criticism of Kuhn, and that these occasional explanations are not in the centre of his interest in SSR.

\subsection{The evolutionary tree analogy after SSR}

After SSR Kuhn uses the fruitful evolutionary tree analogy to describe the pattern of scientific development as a gradual proliferation of specialities (see e.g. [21, 25] ). However the parallel is not entirely sufficient because of some problems and disanalogies. First of all, what is acknowledged by Kuhn himself, "revolutions directly displace some of the concepts basic to the earlier practice in a field in favor of others, a destructive element not nearly so directly present in biological speciation." (Kuhn, 2002: 120 [23]). This means also that specialities do not only evolve but diminish too. Consider Priestley's chemistry which was displaced by Lavoisier's one according to the ruling Newtonian paradigm, that is, the latter one, an evolving speciality of the ruling paradigm displaced the earlier one which was not its speciality. The same influence of the ruling Newtonian paradigm took place in biology in the 19th century because of Darwin's theory of natural selection which was also in accordance with the Newtonian paradigm in lots of aspects in contrast to the theories of the early evolutionists. So, the question is: is there only one tree of science? - Are the Ptolemaen and the Copernican astronomy in the same tree of science? If they are then of what specialities they are? - Because there is only one evolutionary tree.

Secondly, from Kuhn's point of view the evolutionary niches do not determine unambiguously the process of selection 25 "Is

\footnotetext{
24 Completely analogous to this as Sankey thinks that the different, - on the same, lower level still - incommensurable lexicons of theories are comparable in the - higher - level of natural language as metalanguage (Sankey, 1998) [39].

${ }^{25}$ So, they are not only occasional but, moreover, do not determine the way of
}

it the creature who adopts to the word or does the word adopt to the creatures?", asks Kuhn, and then he answers that: "What actually evolve creatures and niches together." (Kuhn, 2002: 102 [25]) Kuhn has right that there is a tight, mutual connection between species and their environment but the consequence of it is not necessarily a kind of relativism - which naturally does not explain any development in science - where "the world is our representation of our niche" (Kuhn, 2002: 103[25]) and thus radically different for us because we are inhabitants of radically and necessarily different and changing niches. However to that, we have to understand these tight and mutual connections and the roles of niches as a complex, multilevelled evolutionary system (see e.g. [6]) and then we can explain the development in nature - and in science - , as we will see it in the third section. Analogous case to this as Kuhn draws a parallel between a gene pool of a species and a lexicon of a scientific speciality. The gene pool is in itself "a sort of individual of which the members of the species are parts. I am persuaded that this example contains important clues to the sense in which science is intrinsically a community activity." (Kuhn, 1993: 329[21]) From the system-theoretical approaches this questionable parallel becomes unambiguous because there are unambiguously identifiable individuals in the different higher system levels (see e.g. [6] ), and thus a cultural group - as well a scientific community - can be an identifiable individual above the level of individual human persons. See, for example, Merlin Donald's “collective conceptual 'model"' (Donald. 1991: e.g. 173[14]).

Finally, the most important thing is that the proliferation of species - the growing complexity - in itself can not explain any development in evolution, thus, in science, it is just a pattern which describes the process. The specification in evolution does not follow necessarily from the theory of natural selection or from the Neo-Darwinian theory. The natural selection can lead to lesser complexity and to lesser specification (see e.g. Darwin, 1872: 99-10026 Maynard Smith, 1997: 4-5; Mayr, 2001: 278$79[7,27,28], 27$

Kuhn himself words the question: "what is the process by which proliferation and lexical change take place?" And answers that "my views remain very close to those developed in Structure." (Kuhn, 1993: 337[21]). This leads us back to the developmental analogy with which Kuhn tries to explain the development in science.

\footnotetext{
adaptation.

26 „In some cases variations or individual differences of a favourable nature may never have arisen for natural selection to act on and accumulate. In no case, probably, has time sufficed for the utmost possible amount of development. In some few cases there has been what we must call retrogression of organisation. But the main cause lies in the fact that under very simple conditions of life a high organisation would be of no service, - possibly would be of actual disservice, as being of a more delicate nature, and more liable to be put out of order and injured." (Darwin, 1872: 99-100 [7])

27 Moreover, a living being's purposeful structure is not simply a matter of complexity (Polányi, 1969: 228)[32].
} 


\section{The developmental analogy}

\subsection{Kuhn's Darwinism}

As we have seen it in the case of the tree analogy, Darwinian analogies can clarify a few problems and contradictions in the SSR. However, if we want to understand the main role of these analogies in the SSR, we have to ask just exactly where and for what purpose they appear in Kuhn's thinking, and what he means by Darwinism.

Kuhn refers to Darwin by name on the last pages of the first edition of SSR (SSR: 171-172). He states that his own sciencedevelopment model is analogous to the Darwinian evolution in a sense that none of them is goal-directed - in contrast to the evolutionary theories before Darwin, and the science-development models of the neopositivists.

"For many men the abolition of that teleological kind of evolution was the most significant and least palatable of Darwin's suggestion. The Origin of Species recognized no goal set either by God or nature. Instead, natural selection, operating in the given environment and with the actual organisms presently at hand, were responsible for the gradual but steady emergence of more elaborate, further articulated, and vastly more specialized organisms. Even such marvellously adapted organs as the eye and hand of man - organs whose design had previously provided powerful arguments for the existence of a supreme artificer and an advance plan - were products of a process that moved steadily from primitive beginnings but toward no goal." (SSR: 172)

But he also states that:

"The developmental process described in this essay has been a process of evolution from primitive beginnings - a process whose successive stages are characterized by increasingly detailed and refined understanding of nature." (SSR: 170)

Beyond doubt Kuhn thinks that this process 'from primitive beginnings' towards an 'increasingly detailed and refined understanding of nature' is at the time not goal-directed, as he thinks the same about the Darwinian evolution, where this 'increasingly detailed and refined understanding of nature' is not identical with the well defined goal of the evolution of science 28 So, we have to ask what the source of this contradiction is, why Kuhn thinks that the Darwinian evolution is an appropriate analogy and finally, what he means under a goal-directed process.

I state here that the Darwinian evolution is goal-directed but, of course, not in the same sense as the theories of progress or the ontogeny - are goal-directed. The main difference between them is that in the case of the Darwinian evolution - and, of course, the development of science - there is no necessary,

\footnotetext{
28 Maybe it is worth noticing that, as we have seen in the end of the 1.4 subsection, the term of ,toward a goal" can be misleading in a sense that the ,,increasingly detailed and refined understanding of nature” is not an explicit, external goal - as that is in the theories of progress - toward which literally the development of science is going but a goal comes from the inside (universal, necessary) structure of science - as that in the ontogeny - in this sense it is determinedly goal-directed.
}

independent developmental pattern or principle - universal scientific standards - which determines the direction and stages - paradigms and scientific revolutions - of the developmental process. In this case, the direction and stages of the developmental process are determined by the subjects of the developmental process, for example, by an ecological system and its parts - or in the case of science the social and technical backgrounds. In contrast to this, in the case of the evolutionary theories of E. B. Taylor, L. H. Morgan and H. Spencer which were influenced by the theories of progress, - or in the case of the neopositivistic science-development models (R. Carnap, K. Popper, etc.) - , there always exists an independent, necessary developmental pattern or principle - universal scientific standards - , which determines the outcomes of evolutionary processes and the subjects of these processes are also subordinated to this independent, necessary developmental pattern or principle. In other words, these processes are not just goal-directed as in the Darwinian evolution and the development of science but their goals are determined by an independent, necessary pattern or principle - set by God, nature, rationality or something else - thus these processes - and the development of science in the neopositivistic theories - become a process of progress.

Kuhn does not see the difference between the two kinds of processes and he thinks that Darwinian evolution is not goaldirected at all. This, however, is not acceptable for a Darwinian.

\subsection{The difference between Newtonian physics and the Darwinian theory of evolution}

It is worth examining how the evolutionary theory of Darwin became an accepted scientific theory and how it was reinterpreted in the general Newtonian paradigm ruling at that time. In this, we ask for Kuhn's help who discerningly sheds light on the reinterpretation of the Newtonian paradigm when it had become an accepted scientific theory according to the dominant mechanistic view of science. So, due to Kuhn, we are able to draw a clear analogy between the two scientific reinterpretations.

We have already seen in the 1.2 subsection and in the $24^{\text {th }}$ footnote that the source of the success of the Darwinian theory was that Darwin cleverly applied the Malthusian demographic mathematical model to natural selection - the main process of his scientific theory. Thus, according to the ruling general Newtonian paradigm, natural selection became a causal mechanism which could unify several very different scientific specialities and their consequences, and which provided and has been providing the fundamental explanatory strength of the Darwinian theory (Morrison, 2000: 202-206 [31]). But, at first, this did not mean that the theory of Darwin was accepted as true, it just meant that it was accepted as a (possible) scientific theory.

However, the causal mechanism of natural selection is not the same that the causal mechanism of Newtonian physics.

"Darwin's theory of natural selection came very late in the history of thought. Was it delayed because it opposed revealed truth, because it was entirely new subject in the history of sci- 
ence, because it was characteristic only of living things, or because it dealt with purpose and final causes without postulating an act of creation? I think not. Darwin discovered the role of selection, a kind of causality very different from the push-pull mechanisms of science up to that time." (Skinner, 1974: 4041 [40])

What is the main difference between the two kinds of causal mechanisms? The answer is that the Darwinian causal mechanism is not necessarily active (e.g. Darwin: 1879, 68-69 [7]). An apple, according to the theory of gravitation, if coming off from a branch of an apple tree, in any case will fall down to the ground and we can predict and draw exactly its trajectory and what is more, the gravitational force is active in every situation (place and time) thus also in the case when the branch of the tree is holding strongly the apple. But, according to the Darwinian theory of natural selection, in the case of an ecological system, we cannot do the same, we cannot predict exactly how, for example, the composition of the species in a given ecological system will change and furthermore when one of its fundamental condition is not appropriate 29 the natural selection is simply not active.

So, the theory of gravitation is a necessary, universal law and in every cases active but the theory of natural selection is just a statistical regularity and only at certain times active. In Popper words: "There are no Darwinian laws of evolution." (Popper, 1983: 267 34] Exactly this is just how the causal mechanism of evolution is directed by the contingent regularities of the evolutionary system.

Thus, contrary to the theory of gravitation, the causal mechanism of evolution does not come into force necessarily in the same way in different but similar cases:

"We have seen that in two beings widely remote from each other in the natural scale, organs serving for the same purpose and in external appearance closely similar may have been separately and independently formed; but when such organs are closely examined, essential differences in their structure can almost always be detected; and this naturally follows from the principle of natural selection. On the other hand, the common rule throughout nature is infinite diversity of structure for gaining the same end; and this again naturally follows from the same great principle." (Darwin, 1872: 165 [7])

In other words, the process of evolution is influenced by internal and external contingencies - biological mutation, the fundamental component of biological evolution, of course, is also of this kind. In the case of gravitation, there are no such internal or external contingences just an independent, universal law.

And what had been the situation before the Darwinian theory

\footnotetext{
29 There are no different variations or environmental pressure.

30 „Darwin's discovery of the theory of natural selection has often been compared to Newton's discovery of the theory of gravitation. This is a mistake. Newton formulated a set of universal laws intended to describe the interaction, and consequent behaviour, of the physical universe. Darwin's theory of evolution proposed no such universal laws. There are no Darwinian laws of evolution."
}

was accepted? In The Origin of Species Darwin complains of this in the following way:

"It has been said that I speak of natural selection as an active power or Deity; but who objects to an author speaking of the attraction of gravity as ruling the movements of the planets?" (Darwin, 1872: 63[7]])

In other words, while the evolutionary theory of Darwin had not been accepted as a (possible) scientific theory according to the ruling Newtonian paradigm, Darwin had been accused that his selection mechanism was a kind of occult, teleological force. But note that Newton was also accused with the same guilt because of his gravitational force. And it is Kuhn himself who discusses this in detail in the SSR and reaches thought-provoking consequences. It is worth examining and trying to comprehend this Kuhnian criticism because it will make clearer what the problem with the interpretation of the Darwinian evolutionary theory of Kuhn is, and in an analogical way, it will make possible a similar criticism on Kuhn himself in connection with the notion of goal-directedness.

"Gravity, interpreted as an innate attraction between every pair of particles of matter, was an occult quality in the same sense as the scholastics' 'tendency to fall' had been. Therefore, while the standard of corpuscularism remained in effect, the search for a mechanical explanation of gravity was one of the most challenging problems for those who accepted the Principia as paradigm. Newton devoted much attention to it and so did many of his eighteenth-century successors. The only apparent option was to reject Newton's theory for its failure to explain gravity, and that alternative, too, was widely adopted. Yet neither of these views ultimately triumphed. Unable either to practice science without the Principia or to make that work conform to the corpuscular standards of the seventeenth century, scientists gradually accepted the view that gravity was indeed innate. By the mid-eighteenth century that interpretation had been almost universally accepted, and the result was a genuine reversion (which is not the same as a retrogression) to a scholastic standard. Innate attractions and repulsions joined size, shape, position, and motion as physically irreducible primary properties of matter." (SSR: 105-106)

This Kuhnian criticism calls our attention to the reinterpretation of the Newtonian paradigm and the notion of goaldirectedness, since before this reinterpretation the gravitational force had been held for an occult, teleological, goal-directed mechanism - from the then ruling mechanical viewpoint of science. But after the reinterpretation, the mechanical view of science became more permissible and it was reconciled with the Newtonian theory of gravity.

So the traditional, neopositivistic contrast is the following:

\section{Aristotelian world view Newtonian paradigm \\ goal-directed not goal-directed}

there is an occult, teleological force there is no occult force 
But on the basis of the Kuhnian criticism the contrast becomes a little bit subtler:

$\begin{array}{ll}\begin{array}{l}\text { Aristotelian world view } \\ \text { goal-directed } \\ \text { there is an occult, } \\ \text { teleological force }\end{array} & \begin{array}{l}\text { Mechanical world view } \\ \text { not goal-directed }\end{array} \\ & \text { there is no occult force }\end{array}$

\section{Newtonian paradigm}

goal-directed ${ }^{31}$

(in a radically new sense) ${ }^{32}$

which is a result of

a (non-occult) force

It is important to emphasize that giving up the earlier, harder interpretation of the mechanical world view - which did not accept any innate attraction between particles and which regarded both the Newtonian paradigm and the Aristotelian world view to be an occult, teleological theory - and the "genuine reversion to a scholastic standard" do not signify a step back for Kuhn but rather a significant and scientifically successful step forward, that is the creation of a kind of synthesis between the old Aristotelian world view as thesis and the mechanical world view of science as antithesis.

In the same way, after the accusations of the $19^{\text {th }}$ century, the same kind of developmental road in the history of science was taken again in connection with Darwin's notion of natural selection. But, of course, the latter was not classified into the same primary properties as the gravitational force but was reduced later into complex physical and biological processes of individual entities (genes) - this was the source of the Neo-Darwinian synthesis (see it in the 1.2 subsection).

All this, however, should not deceive us. Kuhn was not deceived either by the reinterpretation of the gravitation force in the middle of the $18^{\text {th }}$ century. So, without examining the problems of goal-directedness and teleology any further, we can accept that after the interpretational turn, gravitation was no more an occult, teleological force and analogously that, after the First World War, Darwinian natural selection was also not any more seen as an occult, teleological force. 33

\footnotetext{
${ }^{31}$ See its consequence e.g. in Newton's first letter to Bentley (Turnbull, 1961: 234).

${ }^{32}$ We might differentiate between the two senses of goal-directedness in the following way: in the case of the Aristotelian world view call it teleological goal-directedness but in the case of the Newtonian paradigm just a simple goaldirectedness.

${ }^{33}$ It is worth mentioning, however, that the non-teleological notion of natural selection is not acceptable for several contemporary writers too because otherwise it could not be the explanation of any purposeful thing. (See e.g. Polányi, 1962: 345-435 [32]) "The complicated anatomy of the eye like the exact functioning of the kidney are the result of a nonrandom process - natural selection." (Ayala, 1998: 35[2]) But, of course, from the point of view of the system theories it has not to be teleological only goal-directed (see the next subsection).
}

3.3 The goal-directedness of evolution and the developmental analogy

The reinterpretation of the Darwinian theory does not mean that natural selection and the evolutionary process are not goaldirected, as Kuhn himself admits. It just means that the notion of goal-directedness has been radically changed in the Darwinian theory to divert from the meaning of the term in the classic theories of progress and in the theories of the neopositivists. For example, Darwin himself emphasizes over and over again this goal-directedness of natural selection when, in connection with his several examples, he talks about how different species, organs and ecological systems change in a specific, directed way according to the given environmental relations. (E.g. Darwin, 1872: 64 ; 349-350; 401, also see the quotation earlier in subsection 3.2.[7]]).

Kuhn, however, although criticizing it heavily elsewhere, here employs solely the meaning of goal-directedness as it is in use in the old theories of progress and the neopositivists. And, of course, from this uncare point of view, his conclusion is absolutely right that in his sense natural selection and the evolutionary process are not goal-directed.

As a result, Kuhn in his evolutionary analogy contrasts his own science-development model with that of the neopositivists in the following way:

\section{Neopositivistic science- Kuhnian science- development models development model Theories of progress ${ }^{34}$ Darwinian evolutionary theory goal-directed not goal-directed}

This is analogous to the traditional, neopositivistic contrasting of the Newtonian paradigm and the Aristotelian world view. Applying the Kuhnian criticism in an analogous way, as it has been applied in the above case, Kuhn's latter contrasting of the theory of evolution and the notion of goal-directedness also become a little bit subtler:

\section{Neopositivistic science- \\ development models}

Theories of progress

goal-directed

which is a result of an independent, necessary developmental pattern or principle

Darwinian evolutionary theories ${ }^{35}$

goal-directed (in a radically new sense) which is a result of the development of a complex system possessing multiple feedbacks

\footnotetext{
${ }^{34}$ Kuhn mentions H. Spencer and J.-B. Lamarck by name.

${ }^{35}$ Or a Darwinian evolutionary interpretation of the Kuhnian model - in this
} 
In short, the Darwinian evolutionary process differs from both the theories of progress (considered as genuinely goaldirected) and from the physical processes (considered as not goal-directed) in that its coming into force is determined by not independent, strict and universal laws but by individual and statistical law-like regularities, and that the goal and direction and stages of its development are not independent from their subjects. In the words of cybernetics and system theories, the process of evolution is not a simple, linear process of change, composed of individual, independent entities, but is a complex developmental process of multiple feedbacks, composed of many combined, multi-levelled, multi-connected, essentially different entities and its determining principle is not a universal law but an individual, specific stable open system.

All this, of course, were emphasized by Darwin himself, when he said that the different species are connected with each other in several, very complicated ways in the complex ecological systems, and that the process of natural selection, according to the wide biological and environmental conditions and circumstances, is understandable only within these complex systems. See e.g. in the Complex relations of all Animals and Plants to each other in the Struggle for Existence subchapter (Darwin, 1872: 55-59 [7]). And this is the reason why I spoke about a change of an ecological system earlier in the case of my evolutionary example and not about how the giraffe's neck was lengthened. The latter would be simply misleading. And, of course, this does not mean that Darwin himself was already thinking in a complete system theory ${ }^{36}$ but his words are pointing at this direction.

The difference between the two interpretations of the notion of goal-directedness - the one of Darwin and the later neopositivistic/Neo-Darwinian interpretation accepted by Kuhn without careful consideration - is more striking if we put the words of Darwin and the words of Kuhn quoted earlier beside each other. ${ }^{37}$ Kuhn asserts that in The Origin of Species there exists no goal set by nature instead natural selection operates in the given environment, while Darwin himself says in The Origin of Species that the infinite diversities of structure for gaining the same end naturally follows from the principle of natural selection. The words of Kuhn, of course, rely on his thinking of the notion of goal-directedness in a neopositivistic way - for him it can mean only a teleogical notion in the old sence - and not in the very different Darwinian sense.

For Kuhn, the confrontation of natural selection with a goal set by God (or nature) is important, but remember the words of Skinner: the main difference is not this by itself, but the new

case the evolutionary approach, of course, is not taken in a neopositivistic/NeoDarwinian sense.

${ }^{36}$ His interest was radically different as Kuhn himself was not interested in the old sense of paradigm and in the tree structure of scientific theories only in the distinctive role of the exemplars (see it in the 2.5 subsection).

37 Kuhn's words were quoted in the beginning of 3.1 subsection, while Darwin's in the middle of 3.2. kind of causality, because the natural selection "came very late in the history of thought" (where exists no God in the processes of Newtonian physics any more).

\subsection{Conclusions}

To summarize the above, because of his somewhat careless consideration Kuhn uses the neopositivistic/Neo-Darwinian interpretation of evolutionary theory and thus he cannot distinguish between the two notions of goal-directedness. Therefore, his developmental analogy (in contrast to his evolutionary tree analogy) is not acceptable in Darwinian approach, since it cannot explain the contradiction between Kuhn's belief in scientific progress (e.g. SSR: 206) and the fact that he, similarly to that in Darwinian evolution, does not interpret scientific progress as a goal-directed development, just as a process of change. And he also cannot explain in what sense he speaks about a scientific "process whose successive stages are characterized by increasingly detailed and refined understanding of nature" (SSR: 170). So, if Kuhn's aim is to displace the science-development models of the neopositivists, he cannot ask for help from the same neopositivistic/Neo-Darwinian interpretation of the Darwinian evolutionary theory but should turn to the non-neopositivistic/non-Neo-Darwinian cybernetic and system-theoretical approaches of evolution which are goaldirected in the new sense ${ }^{38}$ and the progress or development in science is definable by them.

From a Darwinian point of view of science, the development of science is not just analogous to the process of evolution but, as we have seen examples for that, itself is a (cultural) evolutionary process. And, among other things, this is a goal-directed, cumulative and incommensurabilistic, developmental process, but, of course, not in the above discussed neopositivistic sense ${ }^{39}$ so it is not determined by some independent and necessary principles - e.g. universal scientific standards - , but by wider, not independent social and cultural processes, and by biological and environmental conditions and circumstances 40 at the end by the specific evolutionary system of the Earth. All this, in a sense, is parallel with Kuhn's social-constructivism, yet because of his fundamentally different interpretation of the theory of evolution and its limited application in SSR, in contrast to his intentions, we cannot regard his work as a proper "evolutionary view of science".

\section{Summary}

In my paper, I have argued that the idea of supporting Kuhn's science-development model with a Darwinian theory (against the science-development model of the neopositivists) might be a fruitful and coherent project - as it is in the case of the evolutionary tree analogy - , but to that end, one has to interpret the theory

\footnotetext{
38 Or goal-directed but not teleological.

${ }^{39}$ See its application for example in $\begin{array}{llllll}1 & 2 & 14 & 41\end{array}$

${ }^{40}$ It is quite telling that Kuhn - according to his relativistic attitude - does not think that these processes can be revealed.
} 
of evolution in a non-neopositivistic/non-Neo-Darwinian, indeed 'Kuhnian' way, as it is done by the cybernetic and systemtheoretical approaches but not by Kuhn himself. Otherwise, the Darwinian support for Kuhn's science-development model will be necessarily limited and controversial, and thus we cannot regard Kuhn as a proper Darwinian.

Of course, in another paper we could examine Kuhn's interpretation of the Darwinian theory in connection with not just his goal-directedness but, for example, with cumulativeness, incommensurability, and relativism as well. I suspect we would find in all such cases that Kuhn is committed to a traditional, neopositivistic interpretation of all these different notions.

However, if we try to support Kuhn's science-development model with the cybernetic and system-theoretical interpretation of the Darwinian evolutionary theory which does justice to Darwin, we might solve some problems and contradictions and remove the limits of the standard Kuhnian interpretation. But, of course, such a reinterpretation of Kuhn's work leads to a significantly different science-development model as Kuhn's own.

\section{References}

1 Ashby WR, An Introduction to Cybernetics, Chapman \& Hall LTD, London, 1957.

2 Ayala FJ, Teleological Explanations in Evolutionary Biology in Nature's Purposes., Analyses of Function and Design in Biology (Allen C, Bekoff M, Lauder G, eds.), MIT Press, Cambridge MA, 1998, pp. 29-49.

3 Bertalanffy L von, Kritische Theorie der Formbildung, Harper, New York, 1933.

4 , General System theory: Foundations, Development, Applications, George Braziller, New York, 1968.

5 Bird A, Thomas Kuhn, Princeton University Press, Princeton, 2000.

6 Csányi V, General Theory of Evolution, Akadémiai Kiadó, Budapest, 1982.

7 Darwin Ch, The Origin of Species by Means of Natural Selection, or the Preservation of Favoured Races in the Struggle for Life John Murray, London, 1872 .

8 Dawkins R, The Selfish Gene, Oxford University Press, Oxford, 1976.

9 Dennett D, Darwin's Dangerous Idea, Simon \& Schuster, New York, 1995.

10 Depew DJ, Weber BH, Darwinism Evolving: Systems Dynamics and the Genealogy of Natural Selection, MIT Press, Cambridge, MA, London, 1995.

11 Diamond JM, Guns, Germs, and Steel: the Fates of Human Societies, W. W. Norton, London, 1999.

12 _ The Rise and Fall of the Third Chimpanzee, Vintage, London, 1992.

13 Dobzhansky T, Genetics and the Origin of Species, Columbia University Press, New York, 1937.

14 Donald M, Origins of the Modern Mind: Three Stages in the Evolution of Culture and Cognition, Harvard University Press, Cambridge, MA, 1991.

15 Feyerabend PK, Against Method: Outline of an Anarchistic Theory of Knowledge, Verso, New York, 1997.

16 Fuller S, Thomas Kuhn: A Philosophical History for Our Times, University of Chicago Press, Chicago, 2000.

17 Hanson NR, Patterns of Discovery: An Inquiry into the Conceptual Foundations of Science, Cambridge University Press, Cambridge, 1961.

18 Hoyningen-Huene P, Reconstructing Scientific Revolutions, Thomas S. Kuhn's Philosophy of Science, University of Chicago Press, Chicago, 1993.

19 Huxley J, Evolution: The Modern Synthesis, Allen and Unwin, London, 1942.

20 Kuhn T, Discussion VI in The structure of scientific theories (F. Suppe, ed.), University of Illinois Press, Urbana, 1977.
21 _ Afterwords in World Changes. Thomas Kuhn and the Nature of Science (Horwitch P, ed.), MIT Press, London, 1993.

22 _ The Structure of Scientific Revolutions, The University of Chicago Press, Chicago, London, 1996.

23 _ The trouble with the Historical Philosophy of science in The road since structure: Philosophical essays, 1970-1993, with an autobiographical interview (Conant J, Haugeland J, eds.), University of Chicago Press, Chicago, 2002.

24 _ A Discussion with Thomas S. Kuhn in The Road Since Structure: Philosophical essays, 1970-1993, with an autobiographical interview (Conant J, Haugeland J, eds.), University of Chicago Press, Chicago, 2002.

25 _ The Road Since Structure in The Road Since Structure: Philosophical essays, 1970-1993, with anautobiographical interview (Conant J, Haugeland J, eds.), University of Chicago Press, Chicago, 2002.

26 Laki J, A tudomány természete. Thomas Kuhn és a tudományfilozófia történeti fordulata, Gondolat Kiadó, Budapest, 2006.

27 Maynard Smith J, Szathmáry E, The Major Transitions in Evolution, Oxford University Press, Oxford, 1997.

28 Mayr E, Systematics and the Origin of Species, Columbia University Press, New York, 1942.

29 _ One Long Argument. Charles Darwin and the Genesis of Modern Evolutionary Thought, Harvard University Press, Cambridge, MA, 1991.

30 _ What Evolution Is?, Basic Books, New York, 2001.

31 Morrison M, Unifying Scientific Theories, Cambridge University Press, Cambridge, 2000.

32 Polányi M, Personal Knowledge, Routledge and Kegan Paul, London, 1962. 33 _ Life's Irreducible Structure In Knowing and Being: Essays (Grene M, ed.), Transaction Publishers New Brunswick, London, 1969.

34 Popper K, Logik der Forschung, 1934; English transl. in The logic of scientific discovery, Hutchinson, London, 1960.

35 _ The Rationality of Scientific Revolutions in Scientific Revolutions (Hacking I, ed.), Oxford University Press, Oxford, 1981.

36 _ Objective Knowledge. An Evolutionary Approach, Calderon Press, Oxford, 1983.

37 Reisch G, Did Kuhn Kill Logical Empiricism?, Philosophy of Science $\mathbf{5 8}$ (1991), no. 2, 264-277.

38 Sanderson SK, Social Evolutionism. A Critical History, Basil Blackwell, Cambridge-Oxford, 1990.

39 Sankey H, Taxonomic Incommensurability, ISPS 12 (1998), no. 1, 7-16.

40 Sharrock WW, Read R, Kuhn philosophe of scientific revolution, Polity Press, Cambridge, 2002.

41 Skinner BF, About Behaviorism, Random House, Inc, New York, 1974.

42 Tomasello M, The Cultural Origins of Human Cognition, Harvard University Press, Cambridge, MA, London, 1999.

43 Tomasello M, Carpenter M, Call J, Behne T, Moll H, Understanding and Sharing Intentions: The Origin of Cultural Cognition, BBS 28 (2005), 675735 .

44 Toulmin S, Foresight and Understanding: An Enquiry into the Aims of Science, Harper Torchbooks, New York, 1961.

45 Turnbull HW (ed.), The Correspondence of Isaac Newton, Vol. III, 1961. 1688-1694.

46 Wiener N, Cybernetics or Control and Communication in the Animal and the Machine, MIT Press, Cambridge, MA, 1948.

47 Williams GC, Adaptation and Natural Selection, Princeton University Press, Princeton, N.J., 1966.

48 , Natural Selection: Domains, Levels, and Challenges, Oxford University Press, New York, 1992. 